\title{
A Theoretical Investigation of Surface Glowing Ignition Leading to Gas Flaming Autoignition
}

\author{
NATHASAK BOONMEE ${ }^{1}$ and JAMES G. QUINTIERE ${ }^{2}$ \\ ${ }^{1}$ Department of Mechanical Engineering, Faculty of Engineering \\ Kasetsart University \\ Bangkok, 10900 Thailand \\ ${ }^{2}$ Department of Fire Protection Engineering, University of Maryland \\ College Park, MD 20742 USA
}

\begin{abstract}
A theoretical model for autoignition of wood is developed. The model considers the processes occurring in both solid and gas phases. In the solid phase, a one-dimensional heat conduction model is employed. Char surface oxidation, which can lead to glowing ignition, is taken into account at the solid-gas interface surface. By "glowing ignition", it means the onset of surface combustion. Criteria for glowing ignition are developed based on a surface energy balance. In the gas phase, a transient two-dimensional laminar boundary layer approximation for gas phase transport equations is constructed. The gas phase model is coupled with the solid phase model via the solid-gas interface surface. Flaming autoignition occurs when the maximum gas reaction rate exceeds a critical value. A numerical result from the coupled gas phase and solid phase models shows that autoignition of the combustible gases behaves in two fashions as autoignition type I at high heat flux $\left(\dot{q}_{i}^{\prime \prime}>40 \mathrm{~kW} / \mathrm{m}^{2}\right)$ and autoignition type II at low heat flux $\left(\dot{q}_{i}^{\prime \prime}<\right.$ $40 \mathrm{~kW} / \mathrm{m}^{2}$ ). In the type I autoignition, the flaming occurs just an instant after glowing ignition is initiated, while in the type II autoignition, the solid undergoes glowing ignition long before the flaming is achieved. Comparisons between the theoretical and experimental results are presented to demonstrate capabilities and limitations of the present model.
\end{abstract}

KEYWORDS: flaming autoignition, glowing ignition, fires, wood

\section{INTRODUCTION}

When wood is subjected to an external heat flux, it undergoes pyrolysis process. The fuel volatiles emanating from the pyrolyzed wood will mix with air from the surroundings creating a boundary layer of combustible mixtures. At the same time the boundary layer adjacent to the solid surface is heated by heat conduction from the solid. As a result of the heating, the gas temperature in the boundary layer rapidly increases together with the heat release rate. As the combustible mixtures reach a critical condition, a thermal runaway can be accomplished and gas phase flaming autoignition (hereafter referring as flaming autoignition) occurs without any help of a pilot source.

It has been investigated experimentally [1] and numerically [2] that when the heat flux to the wood surface is high, flaming autoignition occurs relatively fast before char significantly forms on the surface. However, when the heat flux is low, the char formation on the surface is significant. The char layer behaves like a thermal insulator by blocking heat transfer to the virgin wood; hence high surface temperature of the char layer is observed. Because of the high surface temperature, the char layer can react heterogeneously with the oxygen from the surroundings resulting in "surface oxidation" 
and eventually "glowing ignition" [1,2]. The char surface oxidation process is exothermic. It adds energy to the combustible mixtures adjacent to the char surface. Indeed it acts like a pilot source.

In previous theoretical study of glowing ignition of wood [2], a one-dimensional heat conduction model for wood decomposition process including char surface combustion was developed. Criteria for glowing ignition based on a critical point for the surface energy balance was proposed. The numerical results shown that based on the proposed criteria, the numerical results for time to glowing ignition, glowing ignition mass flux and temperature agreed well with the experimental results. In present investigation, the solid phase model has been extended to couple with a gas phase model. The gas phase model is formulated as two-dimensional, transient, laminar, boundary layer approximation with gas density variation. The solid and gas phase models are coupled via the solid-gas interface surface. The objective of the present work is to investigate the physical phenomena underlying surface glowing ignition leading to gas flaming autoignition

\section{EXPERIMENT}

In previous experimental study [1]. An insulated redwood sample $(4 \mathrm{~cm} \times 4 \mathrm{~cm}$ exposed area) was exposed vertically to a radiant heater. The heat fluxes were varied from $30 \mathrm{~kW} / \mathrm{m}^{2}$ to $70 \mathrm{~kW} / \mathrm{m}^{2}$. Ignition time, ignition mass flux, and surface ignition temperature were measured. In present work, the same experimental setup is conducted. The heat fluxes are varied from $30 \mathrm{~kW} / \mathrm{m}^{2}$ down to the heat flux that glowing ignition cannot occur $\left(\sim 10 \mathrm{~kW} / \mathrm{m}^{2}\right)$. The objective of the present experiment is to obtain ignition data of wood under a low heat flux environment where the phenomenon of glowing ignition leading to flaming autoignition is pronounced. Details of the experimental study can be found in [1] and [3]. Here we will use the experimental results as a benchmark to validate the numerical results.

\section{THEORETICAL MODEL}

\section{Assumptions}

The problem considered here is illustrated in Fig. 1. The computational domain is divided into solid phase and gas phase domains. In the solid phase domain, the problem is formulated as a one-dimensional heat conduction in the direction perpendicular to the solid-gas interface surface (i.e., x-direction). The solid phase domain is subdivided into wood and insulator portions. In the wood portion, the wood pyrolysis model including char surface oxidation described in [2] is used to solve for the wood surface temperature char surface oxidation mass flux, and pyrolysis mass flux. In the insulator portion, the surface temperature is calculated from a transient heat conduction equation.

In the gas phase domain, the gas phase transport equations for momentum, energy, and species, are formulated as a two-dimensional transient boundary layer approximation. The following assumptions are imposed in order to simplify the gas phase model: (1) the flow is two-dimensional, laminar, transient buoyancy driven boundary layer flow; (2) the gas mixture behaves like a perfect gas; (3) the gas density change due to a temperature variation is taken into account and the gas density can be calculated directly from the equation of state; (4) the gas thermal properties depend on temperature and can be expressed by a power law relation [4]; (5) the pressure in the computational domain is assumed to be constant at $1 \mathrm{~atm}$; (6) the Lewis number is constant and equal to unity for 
every gas species; (7) the Prandtl number is constant with the value of 0.7 ; (8) the gas radiation absorption is small and can be neglected; (9) the gas kinetic reaction follows a one-step, second-order Arrhenius finite-rate reaction. Prior to ignition the gas reaction rate is small and thus can be omitted from the gas phase transport equations [5, 6]; (10) the gas reaction rate is post-calculated from the successive solution of the gas phase transport equations; (11) flaming autoignition is achieved when the maximum gas reaction rate exceeds a critical value; (12) the gas phase transport equations are coupled with the solid phase model via the solid-gas interface boundary conditions; and (13) the wood surface regression due to the char surface oxidation is neglected. Thus, the gas phase boundary layer approximation is valid for all the simulation time.

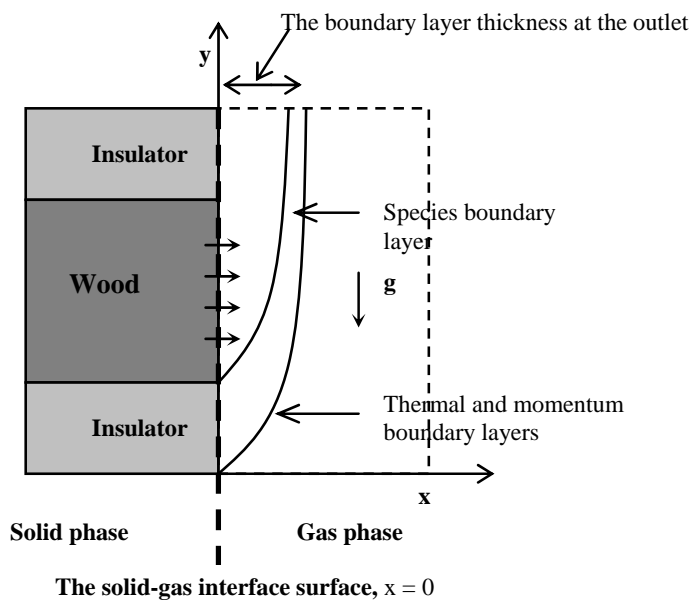

Fig. 1. A systematic diagram for flaming autoignition of wood.

\section{Governing Equations and Boundary Conditions}

For the solid phase, details of the governing equations and boundary conditions are the same as described in [2] and will not present here. For the gas phase model, a twodimensional transient boundary layer approximation for the gas phase transport equations are:

Conservation of mass:

$\frac{\partial \rho_{g}}{\partial t}+\frac{\partial \rho_{g} u}{\partial x}+\frac{\partial \rho_{g} v}{\partial y}=0$,

Conservation of momentum for x-direction (cross-stream):

$\frac{\partial P}{\partial x}=0$

Conservation of momentum for y-direction (streamwise): 
$\rho_{g}\left(\frac{\partial v}{\partial t}+u \frac{\partial v}{\partial x}+v \frac{\partial v}{\partial y}\right)=\frac{\partial}{\partial x}\left(\mu_{g} \frac{\partial v}{\partial x}\right)-\left(\rho_{g}-\rho_{g, \omega}\right) g$

Conservation of energy:

$\rho_{g} C_{P, g}\left(\frac{\partial T_{g}}{\partial t}+u \frac{\partial T_{g}}{\partial x}+v \frac{\partial T_{g}}{\partial y}\right)=\frac{\partial}{\partial x}\left(k_{g} \frac{\partial T_{g}}{\partial x}\right)$,

Conservation of species:

$\rho_{g}\left(\frac{\partial Y_{i}}{\partial t}+u \frac{\partial Y_{i}}{\partial x}+v \frac{\partial Y_{i}}{\partial y}\right)=\frac{\partial}{\partial x}\left(\rho_{g} D_{g} \frac{\partial Y_{i}}{\partial x}\right)$

for $i=F, O$ and

$Y_{t n}=1-\sum Y_{i}$

The gas coordinate system is set as shown in Fig. 1. The solid-gas interface surface is essentially the y-axis. The streamwise direction is the y-direction and the cross-stream direction is the $\mathrm{x}$-direction. The subscript " $g$ " refers to gas. The streamwise velocity component is $v$ and the cross-stream velocity component is $u$. $P$ is the pressure, $T_{g}$ is the gas temperature, and $Y_{i}$ is the mass fraction of species $i$ ( $F$, fuel; $O$, oxygen; $I n$, inert gas). $\mu_{g}$ is the gas kinematics viscosity, $k_{g}$ is the gas thermal conductivity, and $D_{g}$ is the gas mass diffusivity. $\mathbf{g}$ is the gravity $\left(9.81 \mathrm{~m} / \mathrm{s}^{2}\right)$. The $\mathrm{x}$-momentum equation suggests that the pressure is constant across the boundary; thus the pressure variation is only due to the hydrostatic pressure (e.g., $P=\rho_{g} g\left(y_{\text {ref }}-y\right), y_{\text {ref }}$ is the reference level). The hydrostatic pressure combined with the body force is written in the last term on the RHS of the $\mathrm{y}$-momentum equation.

The gas density is evaluated from the equation of state:

$P=\rho_{g}\left(\frac{R}{M_{\text {air }}}\right) T_{g}$,

where $R$ is the universal gas constant $(8.314 \mathrm{~kJ} / \mathrm{kmol} . \mathrm{K}), M_{\text {air }}$ is the molecular weight of air $(28.97 \mathrm{~kg} / \mathrm{kmol})$.

The boundary conditions are

At the inlet $(\mathrm{y}=0)$ : 


$$
u=0 \quad, v=V_{i n}, T_{g}=T_{g, \infty}, Y_{F}=0, Y_{o}=Y_{o, \infty},
$$

At the outlet $\left(\mathrm{y}=\mathrm{y}_{\text {out }}\right)$ :

$$
\frac{\partial u}{\partial y}=\frac{\partial v}{\partial y}=\frac{\partial T_{g}}{\partial y}=\frac{\partial Y_{F}}{\partial y}=\frac{\partial Y_{o}}{\partial y}=0,
$$

At the solid-gas interface, the coupled conditions $(\mathrm{x}=0)$ :

Insulator portions,

$$
\begin{aligned}
& u=v=0, \\
& T_{g}=T_{s}, \\
& \frac{\partial Y_{F}}{\partial x}=\frac{\partial Y_{o}}{\partial x}=0,
\end{aligned}
$$

At the side wall $\left(\mathrm{x}=\mathrm{x}_{\text {side }}\right)$ :

$$
\frac{\partial u}{\partial x}=\frac{\partial v}{\partial x}=\frac{\partial T_{g}}{\partial x}=0 \quad Y_{F}=0, Y_{o}=Y_{o, \infty}
$$

where $V_{\text {in }}$ is the vertical inlet velocity, $T_{g, \infty}$ is the ambient temperature (298 K), $Y_{o, \infty}$ is the ambient oxygen mass fraction (0.233), $u_{s}$ is the blowing velocity, $\dot{m}_{i}^{\prime \prime}$ is the generation rate of fuel $(i=f)$, or the destruction rate of oxygen $(i=O)$, and $T_{s}$ is the solid surface temperature. $\dot{m}_{f}^{\prime \prime}$ and $\dot{m}_{c}^{\prime \prime}$ are the wood pyrolysis mass flux and the char surface oxidation mass flux respectively.

The governing equations and the boundary conditions are normalized with proper length scales. The solid and gas phase governing equations together with the boundary conditions are integrated numerically. The numerical procedure starts by solving the solid phase model for $T_{s}, \dot{m}_{f}^{\prime \prime}$ and $\dot{m}_{c}^{\prime \prime}$ (as described in [2]) providing the boundary conditions for the solid-gas interface, then the gas phase governing equation is integrated with an explicit second-order Runge-Kutta finite difference scheme. After solving the gas phase equations, a new distribution of the heat feedback to the solid surface is computed and then used as a boundary condition in the solution of solid phase equations at the next time-step. A sequence of solving the solid and gas phase models is carried out until the ignition occurs. Prior ignition the gas reaction rate is small due to low gas temperature and thus it is omitted from the gas phase transport equation. This simplification greatly reduces computational difficulty since the computational time is not limited by the chemical time-step, which is typically very small. To determine flaming autoignition, the gas reaction rate is post-calculated from the successive solution of the gas phase model. Flaming autoignition occurs when the maximum gar reaction rate exceeds a predefined value $[7,8]$.

The gas reaction rate is assumed to follow a second-order Arrhenius rate as 
where $\dot{\omega}_{g}^{\prime \prime}$ is the gas reaction rate, $A_{g}$ is the gas pre-exponential factor, $E_{a, g}$ is the gas activation energy, $\rho_{g}$ is the gas density, $Y_{F}$ is the fuel mass fraction, $Y_{o}$ is the oxygen mass fraction, and $T_{g}$ is the gas temperature.

\section{IGNITION CRITERIA}

The solid glowing ignition criteria are based on an energy balance at the solid-gas interface surface. The glowing ignition occurs when the energy gain at the wood surface is greater than the energy loss, which will result in an inflection point on wood surface temperature time history. More details of the solid glowing ignition criteria can be found in [2]. For flaming autoignition, we adopt the autoignition criterion suggested by Nakamura and Takeno $[7,8]$ where flaming ignition will occur when the maximum gas reaction rate $\left(\dot{\omega}_{g, \text { max }}^{\prime \prime \prime}\right)$ is exceed a predefined value. In present gas phase calculations, the ignition occurs when $\dot{\omega}_{g, \text { max }}^{\prime \prime \prime}>0.2 \mathrm{~kg} / \mathrm{m}^{3}$.

\section{RESULTS AND DISCUSSIONS}

Numerical studies of flaming autoignition were performed. The incident heat flux was varied from $20 \mathrm{~kW} / \mathrm{m}^{2}$ to $70 \mathrm{~kW} / \mathrm{m}^{2}$ as a parametric input. The gas phase kinetic parameters were adopted from [7] $\left(E_{a, g}=67 \mathrm{~kJ} / \mathrm{mol}\right.$ and $\left.A_{g}=8.00 \times 10^{5} \mathrm{~m}^{3} / \mathrm{kg} . \mathrm{s}\right)$. An initial ambient oxygen mass fraction $\left(Y_{o, \infty}\right)$ was 0.233 . Comparisons between the numerical results and the experimental data $[1,3]$ are discussed here.

\section{Flaming Autoignition Behavior}

Two types of flaming autoignition were observed from the numerical calculations depending on an incident heat flux: (I) at high heat flux $\left(\dot{q}_{i}^{\prime \prime}>40 \mathrm{~kW} / \mathrm{m}^{2}\right)$, gas flaming autoignition occurs just an instant after solid glowing ignition and (II) at low heat flux $\left(\dot{q}_{i}^{\prime \prime}<40 \mathrm{~kW} / \mathrm{m}^{2}\right.$ ), solid glowing ignition leads to flaming autoignition after considerably delay.

For type I autoignition, when gas flaming autoignition occurs just an instant after the solid glowing ignition, plots of various quantities are shown in Fig. 2 for wood pyrolysis mass flux and surface temperature, insulator surface temperature and gas maximum temperature time histories, and in Fig. 3 for gas temperature and gas reaction rate contours (at the moment of flaming autoignition). The incident heat flux imposed on this calculation is $50 \mathrm{~kW} / \mathrm{m}^{2}$.

The average surface quantities (surface temperature, pyrolysis mass flux) over the wood portion is used to evaluate the wood glowing ignition. Figure 2 shows that the wood undergoes glowing ignition at about 30 seconds. Then just 2 seconds later, the gas mixture achieves flaming autoignition ( $t_{\text {flaming }}=32$ seconds). Due to a very short time interval between wood glowing ignition and gas flaming ignition, the char surface combustion does not significantly increase the wood surface temperature; thus the wood 
surface temperature is still lower than the insulator at the moment of ignition. Consequently, the gas temperature near the insulator surface is hotter than that near the wood surface (see Fig. 3a). Although the gases near the insulator at the lower portion have a high temperature, minor gas reaction rate is observed. This is because the fuel gases cannot propagate upstream due to the buoyancy; the fuel gas concentration upstream remains zero and hence there is no gas reaction rate (Fig 3b). By tracking the maximum gas reaction rate downstream, the onset of flaming autoignition can be determined when the local gas reaction rate exceeds a critical value $\left(0.2 \mathrm{~kg} / \mathrm{m}^{3} . \mathrm{s}\right)$. As indicated above, the gas near the insulator surface at the top portion is hotter than that near the wood surface. Therefore, most of the gas reactions are confined near the top insulator portion. The local maximum gas reaction rate exceeds the critical value at approximately 32 seconds and thus this time is defined as the flaming autoignition time.

As the incident heat flux decreases below $40 \mathrm{~kW} / \mathrm{m}^{2}$, the second type of flaming autoignition is achieved. Depicting the case when the wood surface is heated with $\dot{q}_{i}^{\prime \prime}=$ $30 \mathrm{~kW} / \mathrm{m}^{2}$, the solid glowing ignition leading to flaming autoignition is demonstrated. Figure 4 shows that, the wood surface achieves glowing ignition at about 86 seconds. The additional energy from the char surface oxidation increases the wood surface temperature to be greater than the insulator surface temperature. At the instant of flaming autoignition, the fuel mass fraction near the wood surface is high, however, the oxygen mass fraction is nearly consumed due to the char surface oxidation; the mixture concentration here is extremely rich. As a result, the gas reaction rate near the wood surface is relatively low even though the gas temperature is high (see Fig. 5). As we move way from the wood surface (both horizontally and vertically), the oxygen become more available, and thus the gas reaction rate increases. The high wood surface temperature widens the gas reaction boundary near the wood surface (see Fig. 5b); therefore the gas reaction boundary at low heat flux is thicker than at high heat flux. The blowing due to the fuel pyrolysis mass flux is considerable. Flaming autoignition is detected above the wood surface at approximately 126 seconds.
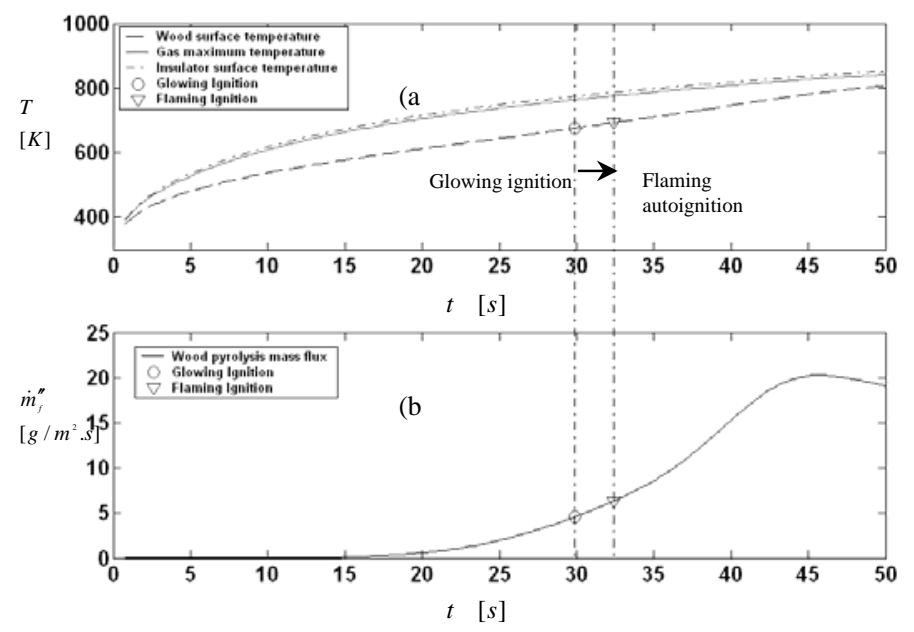

Fig. 2. (a) Gas maximum temperature, and wood and insulator surface temperature time histories and (b) pyrolysis mass flux time history (Autoignition type I, $\dot{q}_{i}^{\prime \prime}=50 \mathrm{~kW} / \mathrm{m}^{2}$,

$$
\left.t_{\text {flaming }}=32 \mathrm{~s}, t_{\text {glowing }}=30 \mathrm{~s}\right) \text {. }
$$



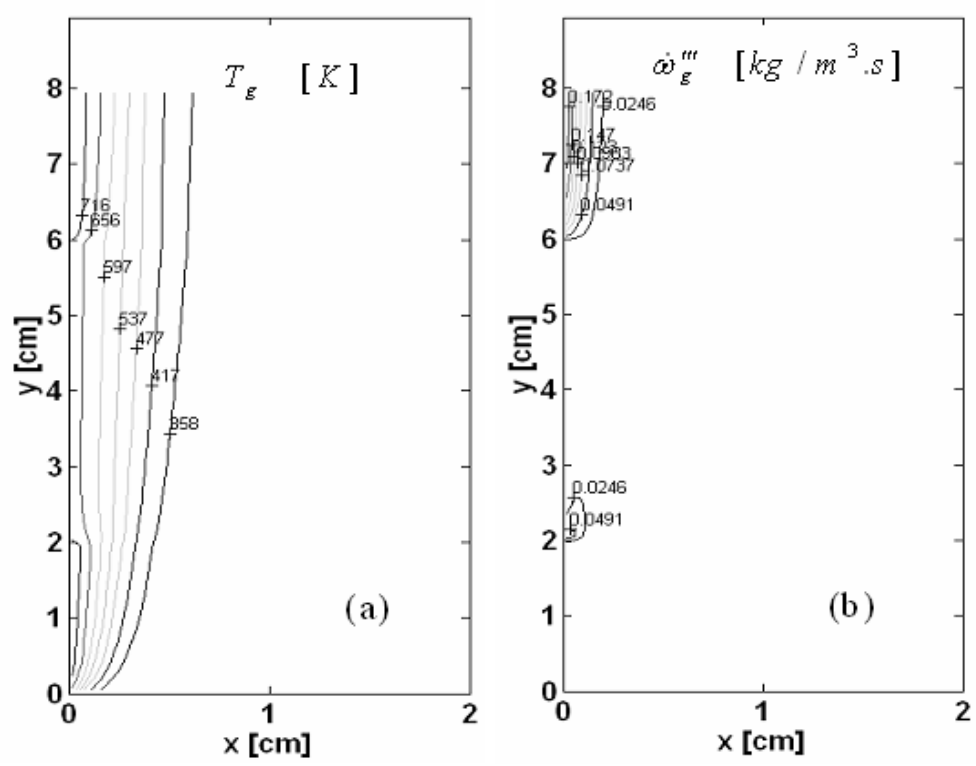

Fig. 3. Contour plots of (a) gas temperature and (b) gas reaction rate at the instant of flaming autoignition (Autoignition type $\mathrm{I}, \dot{q}_{i}^{\prime \prime}=50 \mathrm{~kW} / \mathrm{m}^{2}, t_{\text {flaming }}=32 \mathrm{~s}$ ).

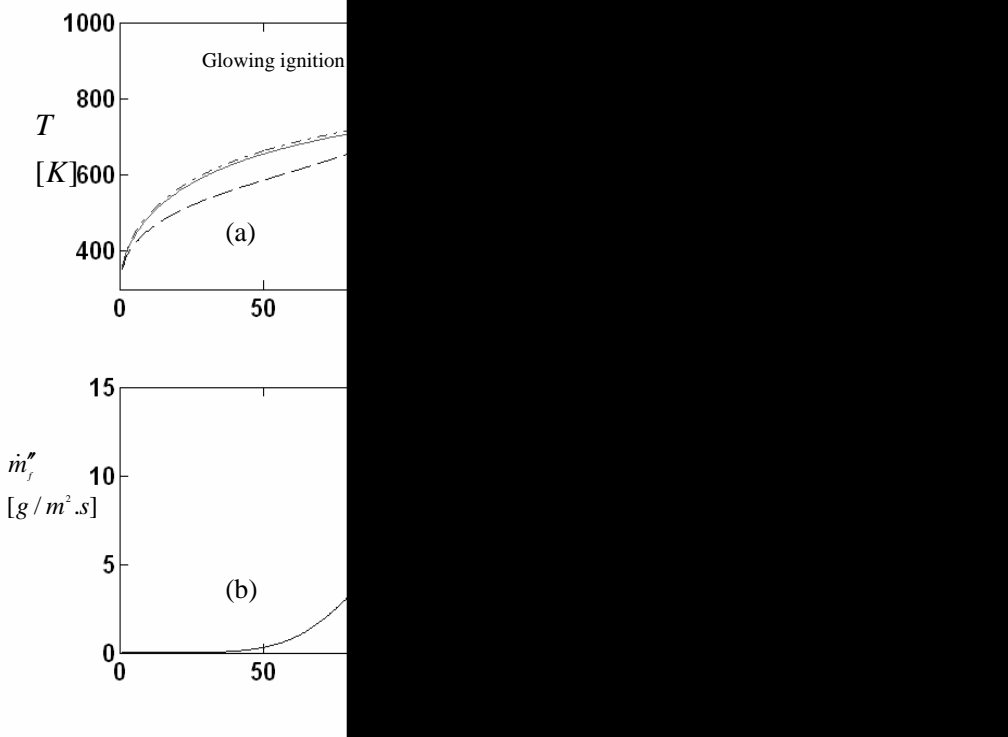

Fig. 4. (a) Gas maximum temperature, and wood and insulator surface temperature time histories and (b) pyrolysis mass flux time history (Autoignition type II, $\dot{q}_{i}^{\prime \prime}=30 \mathrm{~kW} / \mathrm{m}^{2}$,

$$
t_{\text {flaming }}=126 \mathrm{~s}, t_{\text {glowing }}=86 \mathrm{~s} \text { ). }
$$



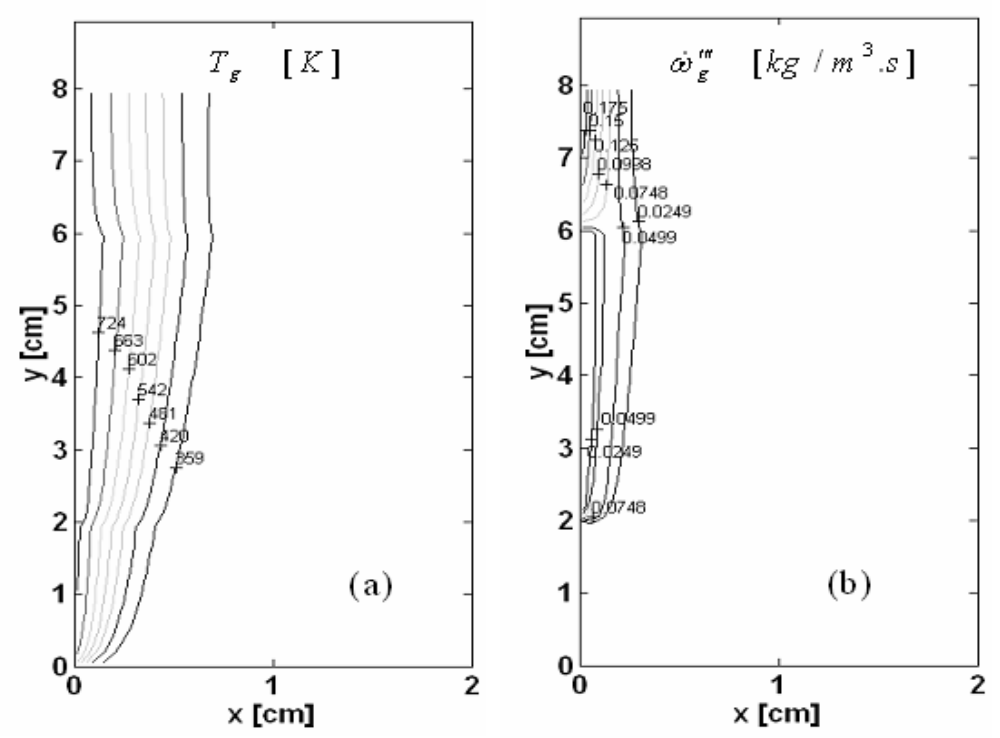

Fig. 5. Contour plots of (a) gas temperature and (b) gas reaction rate at the instant of flaming autoignition (Autoignition type II, $\dot{q}_{i}^{\prime \prime}=30 \mathrm{~kW} / \mathrm{m}^{2}, t_{\text {flaming }}=126 \mathrm{~s}$ ).

\section{Flaming Autoignition: Theoretical and Experimental Results}

Based on the flaming autoignition criterion, an autoignition time delay as a function of incident heat flux is plotted. Figure 6 plots theoretical and experimental times for flaming autoignition and solid glowing ignition as a function of incident heat flux. The experimental data was obtained from [1,3]. At high incident heat flux $\left(>40 \mathrm{~kW} / \mathrm{m}^{2}\right)$, autoignition occurs just an instant after solid glowing ignition (autoignition type I). As the incident heat flux decreases $\left(<40 \mathrm{~kW} / \mathrm{m}^{2}\right)$, a time interval between solid glowing ignition and flaming autoignition considerably increases (autoignition type II). This is because the external heat flux supplied to the combustible mixtures is inadequate to accelerate the gas reaction; thus the flaming autoignition cannot occur. However, as the solid surface undergoes glowing ignition, it supplies an extra energy to the gas mixtures, which can bring the gas temperature to its ignition temperature. This process requires some time interval. This time interval increases as the incident heat flux decreases. It was found experimentally that within 2 hours exposed time flaming autoignition was not observed for heat fluxes lower than $20 \mathrm{~kW} / \mathrm{m}^{2}$. Thus the critical heat flux for flaming autoignition is considered to be $20 \mathrm{~kW} / \mathrm{m}^{2}$. No numerical calculation for heat fluxes lower than the flaming autoignition critical heat flux was performed.

Figure 6 suggests that the calculated flaming autoignition times generally agree well with the experimental data for high incident heat flux. This is because at high heat flux, the gas kinetic reaction is not important. The autoignition basically governs by the solid phase and the heat flux of the external heat source. However, when the incident heat flux is low, the gas kinetic reaction plays a role in the flaming autoignition process. Due to uncertainties of the gas kinetic parameters, the numerical ignition times diverge for the experimental data. 


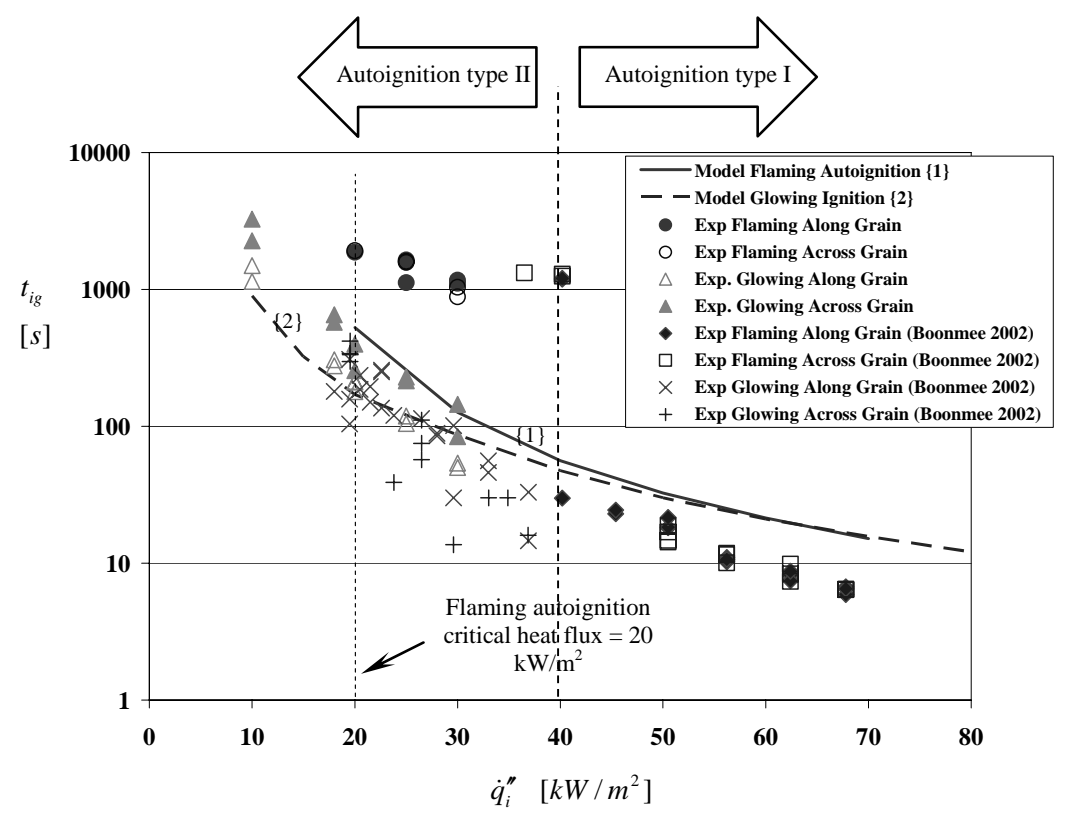

Fig. 6. Flaming autoignition and glowing ignition times as a function of incident heat flux.

\section{Flammability Diagram}

A flammability diagram illustrating the ignitibility of wood is shown in Fig.7. The diagram plots fuel mass fraction $\left(Y_{F}\right)$ on the ordinate and gas temperature $\left(T_{g}\right)$ on the abscissa. Theoretical results for the fuel mass fraction $\left(Y_{F, i q}\right)$ and gas temperature $\left(T_{g, i q}\right)$ at flaming autoignition are plotted on the flammability diagram. $Y_{F, i g}$ ranges from 0.3 to 0.55 which may be considered as the lower and upper limits for flaming autoignition. On the other hand $T_{g, i g}$ is fairly constant. The lowest $T_{g, i g}$ can be considered as the autoignition temperature (AIT); thus here the AIT of wood is about $490^{\circ} \mathrm{C}$. The AIT is fundamentally the temperature at which the combustible mixtures entering the explosion regime [9]. Below the AIT, ignition is not possible unless sufficient external energy is added (e.g., piloted ignition). Zabetakis [10] reported AIT for various fuel-air systems. For instance, the AIT of paraffin hydrocarbons in air ranges from $537^{\circ} \mathrm{C}$ for methane $\left(\mathrm{CH}_{4}\right)$ to $205^{\circ} \mathrm{C}$ for $n$-hexadecane $\left(\mathrm{n}-\mathrm{C}_{16} \mathrm{H}_{34}\right)$. The AIT deceases as the average carbon chain length increases. Quintiere and McCaffrey [11] reported a chemical composition of wood (sugar pine with 6.5\% moisture) as $\left(\mathrm{CH}_{1.74}\right) * 0.0966 \mathrm{H}_{2} \mathrm{O}$ which is relatively closed to a low carbon-atom paraffin hydrocarbon. Thus, it is interesting to point out that the AIT of wood of $490^{\circ} \mathrm{C}$ obtained from the numerical prediction is comparable to those of paraffin hydrocarbons. It is interesting to note that when the gas temperature increases, the lower flammable limit (LFL) decreases. The LFL can be estimated from the adiabatic flame temperature as

$Y_{F, L F L}=\frac{C_{P, g}\left(T_{f, a d}-T_{g}\right)}{\Delta H_{C}}$ 
where $Y_{F, L F L}$ is the lower flammable limit fuel mass fraction, $T_{f, a d}$ is the adiabatic flame temperature $\left(\sim 1300^{\circ} \mathrm{C}\right), \Delta H_{c}$ is the heat of combustion of wood $\left(\sim 12.4 \mathrm{~kJ} / \mathrm{g}\right.$.), and $C_{P, g}$ is the specific heat capacity (taken from air as $1.2 \mathrm{~kJ} / \mathrm{kg} . \mathrm{K}$ ). At a given $T_{g}$ (the gas temperature), we can estimate a corresponding $Y_{F, L F L}$ from Eq. (9). The LFL also plots on the flammability diagram in Fig. 7 to show the trend of piloted ignition and autoignition of wood.

\section{CONCLUSION}

A theoretical model for gas phase flaming autoignition has been developed. Gas phase flaming autoignition is considered to occur when the local maximum gas reaction rate exceeds a critical value. Depending on incident heat flux, two types of autoignition are distinguished. Autoignition type I occurs when the incident heat flux is high $\left(>40 \mathrm{~kW} / \mathrm{m}^{2}\right)$. The flaming autoignition occurs just an instant after the solid glowing ignition. On the other hand, when the incident heat flux is low $\left(<40 \mathrm{~kW} / \mathrm{m}^{2}\right)$, Autoignition type II where the solid undergoes glowing ignition long before the gas flaming ignition is observed. Qualitative agreement between the experimental and theoretical values for autoignition time is demonstrated. Based on the calculation values a flammability diagram of wood can be drawn. The diagram suggests that the autoignition temperature (AIT) of wood is about $490^{\circ} \mathrm{C}$, which is comparable to a typical AIT of paraffin hydrocarbons.

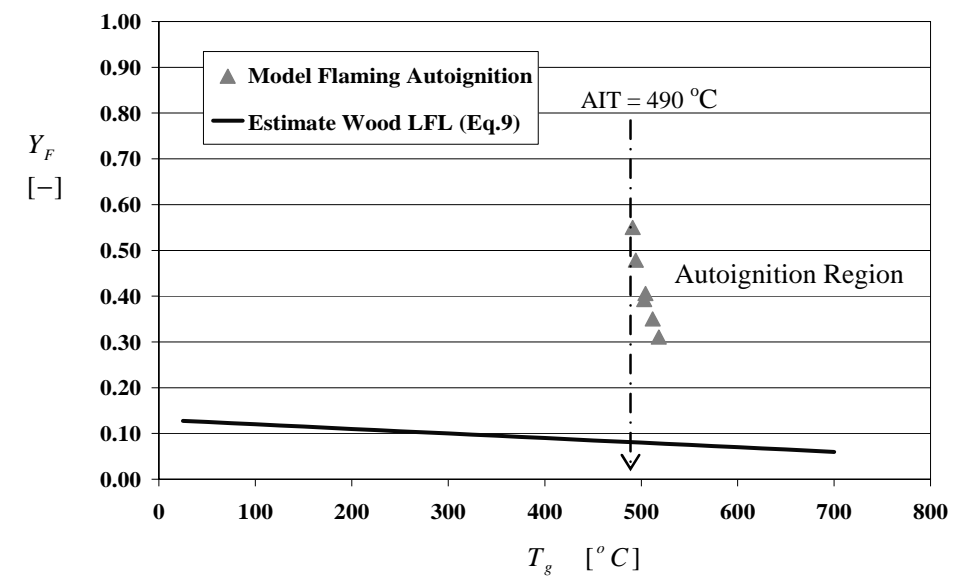

Fig. 7. Flammability diagram of wood.

\section{REFERENCES}

[1] Boonmee, N. and Quintiere, J.G., "Glowing and Flaming Auto-Ignition of Wood," Twenty-Ninth Symposium (International) on Combustion, 2002, 29: p. 289-296.

[2] Boonmee, N. and Quintiere, J.G., "Glowing Ignition of Wood: The Onset of Surface Combustion," Thirtieth Symposium (International) on Combustion, 2005: p. 2303 - 2310. 
[3] Boonmee, N., "Theoretical and Experimental Study of Autoignition of Wood," PhD Dissertation in Mechanical Engineering, 2004, University of Maryland, College Park.

[4] Shih, I.Y. and Tien, J.S., "A Three-Dimensional Model of Steady Flame Spread over a Thin Solid in Low-Speed Concurrent Flows," Combustion Theory Modeling, 2003, 7: p. 677-704.

[5] Zhou, Y.Y., Walther, D.C., and Fernandez-Pello, A.C., "Numerical Analysis of Piloted Ignition of Polymeric Materials," Combustion and Flame, 2002, 131: p. 147-158.

[6] Tzeng, L.S., Atreya, A. and Wichman, I.S., "A One-Dimensional Model of Piloted Ignition," Combustion and Flame, 1990, 80: p. 94-106.

[7] Nakamura, Y. and Takeno, T., "Appropriate Criterion of Spontaneous Ignition of an Externally Heated Solid Fuel in Numerical Study," JSME International Journal, 2001, 44(2): p. 288-298.

[8] Nakamura, Y., Yamashita, H., and Takeno, T., "Effects of Gravity and Ambient Oxygen on a Gas-Phase Ignition over a Heated Solid Fuel," Combustion and Flame, 2000, 120: p. 34-48.

[9] Glassman, I., Combustion. 3rd Edition, 1996, New York: Academic Press.

[10] Zabetakis, M.G., "Flammability Characteristics of Combustion Gases and Vapors," 1965, Bureau of Mines.

[11] Quintiere, J.G. and McCaffrey, B.J., "The Burning of Wood and Plastic Cribs in an Enclosure: Volume I," 1980, National Bureau of Standards. 